\title{
Faculty perception insights obtained from faculty interviews during the development of the Perceptions of Teaching as a Profession in Higher Education (PTaP.HE) instrument
}

\author{
Richard L. Pearson III \\ Department of Physics, Embry-Riddle Aeronautical University, 1 Aerospace Dr, Daytona Beach, FL 32174 \& \\ Department of Physics, Colorado School of Mines, 1523 Illinois St, Golden, CO, 80401 \\ Savannah L Logan and Wendy K. Adams \\ Department of Physics, Colorado School of Mines, 1523 Illinois St, Golden, CO 80401
}

Results from the Perceptions of Teaching as a Profession (PTaP) instrument-which measures views students have of the grade 7-12 teaching career-prompted the development of a parallel instrument to measure the perceptions of the grade 7-12 teaching profession in the eyes of those advising and influencing student opinions of the profession: the faculty. Thirty faculty interviews were conducted across four different institutions of higher education as part of the development of the Perceptions of Teaching as a Profession in Higher Education (PTaP.HE) instrument, which investigates faculty opinions, accuracy of information, and thoughts regarding grade 7-12 teaching. The instrument measures the perceived supportive (or unsupportive) nature of a department towards the teaching profession, guide teacher preparation organizations on how to approach faculty, and correlate students' perceptions with their influencers. Faculty interviews verified statement interpretation consistency, while also providing anecdotal insights into faculty views.

2020 PERC Proceedings edited by Wolf, Bennett, and Frank; Peer-reviewed, doi.org/10.1119/perc.2020.pr.Pearson_III Published by the American Association of Physics Teachers under a Creative Commons Attribution 4.0 license. Further distribution must maintain the cover page and attribution to the article's authors. 


\section{INTRODUCTION}

Statistics regarding the United States' need for discipline-specific secondary (grade 7-12) teachers consistently indicate high demand for those in physics, chemistry, and mathematics [1,2]. On the other hand, a national survey compiled by the APS Panel on Public Affairs shows that nearly half of undergraduate students in physics, chemistry, math, and computer science (more generally known as "STEM" fields) have expressed some level of interest in "being a middle or high school teacher" [3]. To enhance understanding of the gap between those interested in teaching and those employed as secondary education teachers, the Perceptions of Teaching as a Profession (PTaP) survey measures students' "views of teaching as a career, their interest in teaching and the perceived climate of physics departments toward teaching as a profession" [4]. Indeed, national PTaP survey data identified major misperceptions of grade 7-12 teaching that have enabled-though not entirely on their own - the STEM teacher shortage.

In other words, students are making employment decisions based on false perceptions. Faculty are positioned to correct these misperceptions and provide students with fair and equitable advice about career options, since students look to faculty when making career decisions [5, 6]. However, faculty must hold accurate perceptions in order to share accurate data with students; therefore, an instrument is required to measure and quantify the viewpoint faculty hold of grade 7-12 teaching itself. The Perceptions of Teaching as a Profession in Higher Education survey, or the PTaP.HE (stated as "P-taffy"), is specifically designed to measure the underlying, cognitive views college faculty (and staff) have towards secondary teaching.

The PTaP.HE instrument informs college and university departments of their faculty's mindset. Also, its development is a vital part of the recently funded Get the Facts Out (GFO) project, which aims to solve the nationwide STEM teacher shortage by addressing misperceptions held by students and faculty about the teaching profession. This national, interdisciplinary project partners four national societies (the American Physical Society, the American Association of Physics Teachers, the Association of Mathematics Teacher Educators, and the American Chemical Society) to help facilitate the distribution of resources to combat misperceptions. The PTaP.HE couples with the PTaP to (1) motivate resource use, and (2) measure potential progress among both populations.

Faculty interviews play a key role in the development of the structure and focus of the PTaP.HE instrument. Section II describes them within the context of instrument development and consistent statement interpretation. Section III recounts faculty statements and insights collected from the interviews and relates those with student perception outcomes derived from the PTaP.

\section{IMPACT OF INTERVIEWS ON DEVELOPMENT}

The need for a faculty perceptions instrument was identified in 2015 by the Physics Teacher Education Coalition (PhysTEC) community when work first began on the student-facing PTaP. At the time, both faculty and student perceptions were untested; approaching faculty colleagues about their perceptions seemed too uncomfortable within the PhysTEC community so work was limited to student perceptions. However, a direct biproduct of the PTaP's quantification of student misperceptions (the initial work to address those perceptions) and the funding of GFO was the PhysTEC community's openness to a facultyfacing edition.

\section{A. Developmental interviews}

Perception surveys and concept inventories (such as the PTaP [4], CLASS [7, 8], and TOAST [9]) follow a general but consistent four-phase development and validation structure as summarized by Ref. [10] and to which the PTaP.HE development generally adheres. The developmental interviews of Phase Three follow the instrument structure details in Phase One and Two. Validation efforts in Phase Four are beyond the scope of the present paper but will follow in forthcoming PTaP.HE publications.

\section{Phases One \& Two}

Phase One delineates the purpose and scope of the PTaP.HE: measure the perceptions faculty members hold regarding the grade 7-12 teaching profession. General faculty responses are scored against publicly available facts and expert faculty opinions. "Experts" are defined as those actively and successfully involved with the recruiting and preparation of teacher candidates. Though the scope of the PTaP.HE is on university or college faculty, the generality of the "HE" - or "higher education"-domain includes all those involved in the education, advising, and overseeing of undergraduate students.

The instrument specifications outlined in Phase Two include forced answer statements which provide consistently reliable scoring across departments and institutions, encourages higher completion rates, and lowers completion time. The latter was of particular importance when developing the PTaP.HE, as faculty time is extremely limited. Therefore, we began with the goal of creating a twenty-item instrument that could fairly represent the ideas shaping faculty perceptions. Nevertheless, the final product includes 35 five-point Likert-scale statements and 5 multiple-choice questions that can be completed in an online survey in $\sim 9$ minutes. making it convenient to include at the beginning of faculty meetings or other institutional faculty gatherings; the list of statements can be found at Ref [11]. 


\section{Phase Three}

Ref. [10] details specific steps to develop a typical "Formative Assessment of Instruction" tool within Phase Three. The steps adopted and combined to the developmental specifications of the faculty-facing assessment are as follows:

(i) Establish topics that are important to college or university departments and create open-ended survey questions to probe faculty thinking more broadly in test form;

(ii) Through developmental interviews and observations, identify "faculty thinking" on these topics and the various ways it can deviate from "expert thinking" through a forced answer survey given to both novices and subject experts; and

(iii) Administer the survey to faculty and carry out validation interviews.

The structure of the PTaP.HE development varies slightly from the prescribed structure stated in Ref. [10] because much of the foundational legwork was completed with the PTaP development. Additionally, the intertwined dependence of the Get the Facts Out project and the PTaP.HE also placed undesirable time constraints on its development. Generally, the steps were combined. Each is discussed in further detail below in their combined fashion.

Step (i): Development of preliminary survey statements. The initial set of forced answer statements consisted of ideas from two primary sources: the PTaP survey and faculty discussions. Selected PTaP statements were re-worded to represent a faculty's viewpoint. In the second, faculty discussions during national and local workshops designed specifically to "bust myths" about the teaching profession prompted the creation of items regarding effective teacher candidate recruitment [12]. Approximately 50 statements comprised the initial PTaP.HE instrument, with three of those statements posed as open-ended questions meant to gather additional information to encompass important topics. No other open-ended responses were necessary due to the legwork of the PTaP and the prior faculty workshop discussions in exploring the domain.

This original group of statements covered faculty perceptions of teacher salary, benefits, retirement, job satisfaction, intellectual stimulation, scientific identity, and student interest in teaching, as well as faculty advising and recruitment practices.

Step (ii): Faculty interviews and further development of statements. In-person faculty interviews verified the interpretation consistency of all statements and ensured identification of all perception topics. The thirty 45-minute faculty interviews followed think-aloud protocols, where participants are asked to "verbalize their thoughts" while completing the survey [13]. Clarification inquiries and additional explanations of specific items sought by the interviewer came after participants completed the entirety of the survey, allowing the think-aloud responses to remain untainted. Faculty were then asked if they felt the survey covered all the important aspects of grade 7-12 teaching. Per the advice given in Ref. [10], the interviewer compiled and assessed both a summary of the interview and the faculty's responses immediately following an interview's conclusion.

Appropriate adjustments to the survey statements followed assembled interview results and summaries. The modifications extended from slight (e.g., re-wording a statement for better clarification, such as changing "I consider grade 7-12 teaching a STEM career" to "I consider grade 7-12 math or science teaching a STEM career," (emphasis added) to complete removal (i.e., discarding a statement due to its ineffectiveness when nearly all responded similarly). Again, the main purpose of the thinkaloud interview process ensures that the audience-in this case, the faculty-interprets individual statements in the same manner and identifies topics appropriately and consistently.

Of the three original, open-ended survey questions, only one became a forced answer multiple-choice question ("What percentage of STEM students do you think expressed some level of interest when answering the following statement: How interested are you in being a middle or high school teacher?"). The other two paired with included Likert-scale statements and were subsequently removed when it was apparent those statements were suitable.

Interview-based statement adjustments iterated 8 times, with a total of 27 interviews conducted during that process. The number of interviews completed before adjusting statements varied, depending on the type of modification implied from the interview. The faculty interviews highlighted misunderstandings of the PTaP.HE statements and provided insights that shaped the focus of the instrument.

Step (iii): Follow-up interviews. Three additional interviews were conducted after statistical analysis of data collected from the PhysTEC community prompted removal or combination of about a fourth of the statements. These follow-up interviews once again confirmed consistent flow and response reasonings of the survey items.

\section{B. A closer look at the interviewees}

Table I details the demographics of the 30 interviewed faculty. Highlights are given here:

- Most of the interviewees came from public universities in two U.S. states.

- The majority were professors but note that $10 \%$ of those interviewed were currently filling the role of "Chair."

- Though the interviewees came from various departments and backgrounds, nearly all felt they supported or were amenable to teaching as a profession.

To the last point, many of the initial contacts made at these institutions redirected - or, as in the vernacular, "dodged and deflected"- the interview invitation to a faculty member seen as fairly agreeable to the secondary teaching profession. 
TABLE I. Interviewee demographics

\begin{tabular}{lcc}
\hline \multicolumn{1}{c}{ Category } & $\begin{array}{c}\text { Number } \\
\text { of faculty }\end{array}$ & $\begin{array}{c}\text { \% of } \\
\text { faculty }\end{array}$ \\
\hline Representative departments & 14 & $46 \%$ \\
Physics & 5 & 17 \\
Chemistry & 5 & 17 \\
Mathematics & 6 & 20 \\
Other STEM disciplines & & \\
Faculty role & 21 & $70 \%$ \\
Tenure \& Tenure-track & 7 & 23 \\
Full-time, non-tenure & 1 & 3 \\
Part-time, non-tenure & 1 & 3 \\
Administration & & \\
Institution type (no. of institutions) & 25 & $83 \%$ \\
Public university (4) & 3 & 10 \\
Private university (1) & 2 & 7 \\
Community college (2) & & \\
Gender & 15 & $50 \%$ \\
Female & 15 & 50 \\
Male & & \\
\hline \hline
\end{tabular}

Consequently, many of the interviewees were likely more positive than the typical faculty regarding grade 7-12 teaching. Nevertheless, the diversity of faculty, departments, and institutions helps support the effectiveness of the interview process by ensuring that faculty with a variety of viewpoints and experiences were able to consistently interpret the PTaP.HE statements. As seen in the interview highlights in the following section, the cohort of faculty interviewees oftentimes displayed inaccurate perceptions of the grade 7-12 teaching profession. Therefore, the effect of the apparent selection bias of the purportedly supportive faculty is diminished.

\section{INTERVIEW INSIGHTS}

The sample size of faculty interviews during the development of the PTaP.HE do not permit a statistically meaningful quantitative discussion of general faculty perceptions. However, a display of faculty remarks and declarations from the think-aloud interviews illustrates the significant impact made on the PTaP.HE instrument. Common themes are also described within the context of the interview cohort. Selected faculty responses are grouped according to topics identified on the PTaP.HE. Occasional comparisons are made to student perceptions acquired from the PTaP [4].

\section{A. Happiness}

Though the interviewed faculty view grade 7-12 teaching as a reasonable and fulfilling career for a STEM major, their perceptions of just how well teachers feel they are doing in their lives is poor; similarly (per the PTaP data from Ref. [4]), students also think teachers are unhappy. In contrast, a recent Gallup survey found that "teachers in the United States rate their lives better than all other occupation groups, trailing only physicians" [14]. In other words, teachers rate themselves as having the second-highest well-being out of all professions, illustrating that teachers generally enjoy what they do and enjoy the life that comes with it.

Interviewed faculty perceive grade 7-12 teaching as an "intellectually stimulating" career, as illustrated by two faculty statements: "You learn more as a teacher" and "If you do it right, it will be [an intellectually stimulating career]." Indeed, the American Institute of Physics found that teaching is slightly more "intellectually stimulating" than other private sector STEM jobs [15]. Yet this perception does not carry over to the perceived happiness of grade 7-12 teachers. At some point during the interview, about $80 \%$ of faculty made a negative statement associated with teacher's happiness or efforts: teachers are "unhappy", have "great difficulty", have immense "stress", or have a "hard, tough job". This distinction in perceptions underlies the importance of propagating appropriate and legitimate facts about teaching to faculty and prospective teachers.

\section{B. Retirement}

Interviewed faculty seemingly understood retirement benefits available to teachers and the competitive nature of those benefits as compared to other employment options. One faculty highlighted that "there are a lot of careers that don't [have competitive benefits]." It may be that those interviewed have similar retirement benefits, or that they have already had to address retirement and its impact on their life. Conversely, the PTaP showed students lacking in teacher retirement benefit knowledge [4]. Faculty often commented, however, that students were not interested in retirement; nevertheless, the opposite is true [16].

\section{Autonomy and agency}

The interviewed faculty expressed interest in the autonomy - the unique control of what and how teachers teach - of the grade 7-12 teacher. Several interviews in succession added "autonomy" as an item on the PTaP.HE. Half of the faculty in our small cohort perceive grade 7-12 teachers as lacking autonomy in their classrooms due to administration, bureaucracy, and/or regulatory state testing. Interestingly, secondary teachers themselves generally feel they have control in their classrooms; more than $90 \%$ perceive at least some control, or agency, of selecting teaching techniques, student assessment, discipline, and homework designation (with a sample size of around 5,000) [17]. Though, the amount of autonomy varies between specific schools, districts, and states, faculty must be equipped with correct information to relay to interested parties (students, parents, administration, etc.).

\section{Salary}

From our interviews, faculty generally perceive a $\$ 5,000$ $\$ 10,000$ gap when estimating a first-year teacher salary and a "typical," permanent job. Comparatively, students 
generally estimate a pay difference of $\$ 30,000$, which indicates faculty seem to have a better understanding of the job market [4]. Still, this is an important aspect to discuss and identify with faculty members as national salary surveys continue to show equivalent starting salaries for many fields [18]. Even with a smaller perceived gap, the view from nearly $90 \%$ of the faculty interviews can be summarized in one faculty's statement: "Teachers don't go into teaching for the money." Research from the GFO project indicates that it is necessary to identify local data and salary information to discuss the teaching profession with appropriate salary context [19].

\section{E. Retention}

Seventy-nine percent of grade 7-12 teachers are still teaching after 5 years [20]. Faculty interviewees underestimated that number by nearly $30 \%$. The retention rate indicates the profession's stability and may even be used as an indicator of happiness. Yet the interviewed faculty may be underselling this STEM profession if discussing retention rates or job security.

\section{F. Student interest in teaching}

As highlighted at the beginning of this paper, nearly $50 \%$ of STEM undergraduates have expressed some level of interest in middle or high school teaching [3]. When faculty were asked to estimate the percentage of students who they thought had some interest in secondary teaching, responses averaged around $10 \%$, regardless of the specified student population (either within the department, college, or campus-wide). In fact, the interviewed faculty found the $50 \%$ number so unbelievable that this eventually required a re-phrasing of the statement and a conversion to a multiplechoice selection. One faculty member stated that "Most [students] have already chosen what to do..." implying that even if it was true, students would not change course. Still, this does not alleviate the fact that half of their science, engineering, and mathematics undergraduate students have some interest in secondary teaching.

\section{G. Passion}

When faculty answered, "I would feel comfortable if one of my strongest students became a grade 7-12 teacher," they all agreed. However, about a third included a clarifying statement, such as "Only if [the student is] passionate," or "Yes, if that is what [the student] wanted to do," or "No problem - if they want to do it!'. This perception implies that one can only handle being a grade 7-12 teacher if one has "passion." To try and normalize a faculty's response, two added items on the PTaP.HE inquire about how one would feel about a strong student going to "graduate school" or into "industry". Preliminary interview results $(n=2)$ still attach a "passion" to grade 7-12 teaching.

\section{H. Student advising}

In the first iterations of the PTaP.HE, faculty responded to a statement addressing their advising activities towards students who had indicated an interest in teaching. While nearly $85 \%$ of interviewed faculty stated they had indeed offered support and direction, half of the faculty did not regularly discuss grade 7-12 teaching as a career optioneven if they had indicated to regularly discussing career options with students. One faculty member acknowledged this disconnect: "[I] might be wrong to not talk to [students] about it." This highlights the unnecessary division set between grade 7-12 teaching and other STEM career conversations with undergraduates.

\section{Scientific identity}

Faculty responses varied widely regarding grade 7-12 teacher scientific identity, as illustrated by these two statements: "[Though they are] Not a professional scientist, [they are] not giving up being a scientists; once a scientist, always a scientist"; as compared to "They are not scientists or engineers; they are teachers." Scientific identity is impactful in a teacher's continued learning, adjustment, and professional growth [21]. Therefore, faculty perceptions must be aligned to properly encourage and prepare preservice teachers, or anyone showing an interest.

\section{CONCLUSIONS}

The Perceptions of Teaching as a Profession in Higher Education instrument is a companion to the student-facing Perceptions of Teaching as a Profession instrument, which both measure the perceptions towards the grade 7-12 teaching career. In total, 30 think-aloud, in-person, faculty interviews directed eight iterations of the PTaP.HE. Indeed, the overarching purpose of the interviews during instrument design is to iterate initial statements, looking for both consistent interpretation and untested perceptions.

Faculty interview responses provide insight to the thoughts of faculty toward grade 7-12 teaching. Though a statistically verbose dataset is beyond the scope of this work, the faculty statements illustrate opinions in a cohort, generally biased in support of grade 7-12 teaching. It thereby emphasizes the significance of the negative faculty quotations: if the interviewed faculty are champions of grade 7-12 teaching, how does the average faculty feel about grade 7-12 teaching as a profession?

\section{ACKNOWLEDGEMENTS}

The authors thank the thirty interviewed faculty who provided so many guiding comments and suggestions. This work is part of the Get the Facts Out project (NSF DUE1821710 \& 1821462). Any opinions, findings, and conclusions or recommendations expressed in this material are of those of the author(s) and do not necessarily reflect the views of the NSF. 
[1] Educator Supply and Demand Report 2014-2015. American Association for Employment in Education (2015).

[2] Educator Supply and Demand Report 2018-2019. American Association for Employment in Education (2019).

[3] M. Marder, R. C. Brown, and M. Plisch, Recruiting Teachers in High-Needs STEM Fields: A Survey of Current Majors and Recent STEM Graduates, A Report for the American Physical Society Panel on Public Affairs (American Physical Society, College Park, MD, 2017).

[4] W. K. Adams, A new survey uncovers strong misperceptions about the teaching profession: What can we do to get the facts out? APS Forum on Eduction Fall 2017 Newsletter (2017).

[5] 2017 College Student Survey: A Nationally Representative Survey of Currently Enrolled Students. Strada-Gallup (2017).

[6] Major Influence: Where Students Get Valued Advice on What to Study in College. Strada Education Network and Gallup, Inc. (2017).

[7] W. K. Adams, K. K. Perkins, M. Dubson, N. D. Finkelstein, and C. E. Wieman. The design and validation of the Colorado Learning Attitudes about Science Survey, in AIP Conference Proceedings, Sacramento, CA (2005), edited by J. Marx, P. Heron, S. Franklin, 790, 45.

[8] W. K. Adams, K. K. Perkins, N. S. Podolefsky, M. Dubson, N. D. Finkelstein, and C. E. Wieman. New instrument for measuring student beliefs about physics and learning physics: The Colorado Learning Attitudes about Science Survey, Phys. Rev. ST Phys. Educ. Res., 2, 010101 (2006).

[9] S. J. Slater. The development and validation of the Test Of Astronomy STandards (TOAST), Journal of Astronomy \& Earth Sciences Education (JAESE), 1, 1 (2015).

[10] W. K. Adams and C. E. Wieman. Development and validation of instruments to measure learning of expert-like thinking, International Journal of Science Education, 33, 9, (2011).
[11] Perception Surveys (PTaP and PTaP.HE). Accessed at https://GetTheFactsOut.org/perceptions-surveys-ptap-andptaphe (2020).

[12] K. Callan, W. K. Adams, and L. Cleveland. MythBusters: Interventions to address and correct misperceptions about the teaching profession, APS Forum on Education Spring 2018 Newsletter (2018).

[13] K. A. Ericsson and H. A. Simon. Verbal reports as data, Psychological Review, 87, 3 (1980).

[14] S. J. Lopez and P. Sidhu, Gallup-Healthways Well-Being Index at https://news.gallup.com/poll/161516/teachers-lovelives-struggle-workplace.aspx, accessed January 2020.

[15] P. Mulvey and J. Pold, American Institute of Physics Statistics, Physics Bachelor's Initial Employment: The 2011 and 2012 Follow-up surveys of Physics Bachelor's, 2015.

[16] J. E. Brown, Millennials and Retirement: Already Falling Short. National Institute on Retirement Security (2018).

[17] 2017 Educatory Quality of Work Life Survey. The American Federation of Teachers (2017).

[18] Salary Survey Spring 2017. National Association of Colleges and Employers (2017).

[19] S. L. Logan, R. L. Pearson III, and W. K. Adams. GFO copywrite: Development and testing of written and visual materials for recruiting STEM teachers, in 2019 PERC Proceedings, Provo, UT (2019), edited by Y. Cao, S. Wolf, and M. Bennett, https://doi.org/10.1119/perc.2019.pr.Logan.

[20] Public School Teacher Attrition and Mobility in the First Five Years. United States Department of Education (2015).

[21] L. Avraamidou. Studying science teacher identity: Current insights and future research directions, Studies in Science Education, 50, 2 (2014). 